A escolha do cônjuge: uma categoria de análise nas Ciências Sociais.

Revista Ensaios, vol. 14, jan-jun de 2019.

\title{
A escolha do cônjuge: uma categoria de análise nas Ciências Sociais
}

\author{
Breno Rodrigo de Oliveira Alencar ${ }^{1}$ \\ Carmem Izabel Rodrigues ${ }^{2}$
}

Resumo: Os arranjos matrimoniais são uma importante fonte de análise do modo como um grupo ou a totalidade da sociedade se organiza. A partir de uma revisão bibliográfica que teve como objetivo mapear as pesquisas sobre este assunto, o presente ensaio sugere a existência de correntes teórico-metodológicas que implicaram no surgimento, desenvolvimento e estabelecimento da escolha do cônjuge como um importante objeto de estudo para as ciências sociais. Adotando como ponto inicial as problematizações da escolha no pensamento social pós-iluminista combinada as suas implicações em diferentes áreas do conhecimento e na vida social, procuramos demonstrar que os avanços e limitações das técnicas de pesquisa e interpretações empregadas por estes estudos fazem da escolha do cônjuge uma pertinente categoria de análise da identidade, interação e ação social em sociedades complexas.

Palavras-chave: Escolha; Casamento; Teoria Sociológica; Ação Social.

\section{The choice of the spouse: a category of analysis in the social sciences}

Abstract: Marriage arrangements are an important source of analysis of how a group or the totality of society organizes itself. Based on a bibliographical review that aimed to map the research on this subject, the present essay suggests the existence of theoreticalmethodological currents that implied the emergence, development, and establishment of the spouse's choice as an important object of study for the social sciences. Adopting as a starting point the problematizations of choice in post-Enlightenment social thought combined their implications in different areas of knowledge and social life, we try to demonstrate that the advances and limitations of the research techniques and interpretations employed by these studies make the choice of the spouse a relevant category of analysis of identity, interaction, and social action in complex societies.

Keyword: Choice; Marriage; Sociological Theory; Social Action.

\footnotetext{
${ }^{1}$ Instituto Federal do Pará (IFPA), Belém, PA, Brasil. breno.alencar@ifpa.edu.br.

${ }^{2}$ Universidade Federal do Pará (UFPA), Belém, PA, Brasil. cir@ ufpa.br.
} 
A escolha do cônjuge: uma categoria de análise nas Ciências Sociais.

Revista Ensaios, vol. 14, jan-jun de 2019.

Enquanto prática entre o conjunto de práticas sociais reproduzidas que definem a família como sistema social, a escolha do cônjuge revela ser, através da propensão para a homogamia social, um momento fundamental da estrutura social, ou seja, um dos modos por via dos quais a estrutura social é reproduzida (Rosa, 2008, p. 82).

O objetivo deste ensaio é levantar uma discussão teórico-metodológica e, ao mesmo tempo, mapear as pesquisas realizadas sobre o tema da escolha conjugal. Não pretendemos com isso esgotar o assunto ou os textos citados, como também não é nossa intenção discorrer apenas sobre aqueles textos que explicitamente tratam do assunto em tela. Na verdade, a intenção foi fazer uma seleção de textos em meios às diferentes disciplinas das ciências sociais que pudessem nos orientar no sentido de perceber como se tem construído, teoricamente e na prática, a pesquisa sobre o processo de seleção da parceria afetivo-sexual.

A pertinência do tema foi identificada durante a realização de um levantamento bibliográfico no qual se constatou um aumento no número de estudos que abordam arranjos domésticos e familiares em meio as tensões provocadas pelas recentes alterações na composição demográfica de países ocidentais no tocante aos efeitos da mudança na legislação sobre o divórcio, o direito a união entre homossexuais, a produção independente e o reconhecimento das famílias monoparentais (Alencar, 2011). Nesse cenário o principal questionamento se situa entorno do significado do casamento em sociedades chamadas de complexas, onde a variedade de interações sociais impõe experiências de sociabilidade que transformam essa pauta em um assunto íntimo e que se justapõe a uma densa rede de opções afetivas e sexuais que tende a desalojar, cada vez mais, a visão institucionalizada do casamento em benefício de uma escolha voluntarista.

Conforme observam vários autores essa transformação é uma sensação comum no meio urbano de países desenvolvidos e tem sido singularmente favorecida pela decisão unilateral dos sujeitos - e não mais as suas famílias ou a comunidade - em escolher seus cônjuges assim como pela oficialização ou não da aliança (Bozon e Héran, 1987 e Bozon e Héran, 1988). Neste sentido, a escolha do cônjuge representaria uma das principais consequências do individualismo contemporâneo pois acompanha as principais dinâmicas observadas no âmbito do casamento e da família no último século (Pugeault, 
A escolha do cônjuge: uma categoria de análise nas Ciências Sociais.

Revista Ensaios, vol. 14, jan-jun de 2019.

2010). Dados estatísticos são sugestivos a este respeito e uma seleção baseada nos principais países dos continentes Europeu e Americanos apontam para um cenário comum:

Com base na Tabela 1 (final do artigo) podemos notar, por exemplo, a redução generalizada da proporção de indivíduos casados nos países selecionados, ao passo que aumentou, no mesmo período, o número de solteiros e separados ou divorciados ${ }^{3}$. O Gráfico 1 (final do artigo), por sua vez, permite notar o adiamento progressivo da idade ao casar em todos os países selecionados. Refletindo as mudanças econômicas observadas ao longo do período, o enfraquecimento dos constrangimentos familiares e da própria obrigação do casamento como estilo de vida, essa mudança demográfica sugere que o casamento nas sociedades ocidentais está passando por um processo de "desritualização", cujo caráter "oficioso" podem estar dando lugar a outras "necessidades" ou serem abandonados como modalidades de arranjo social.

Se por um lado estamos diante de um processo de transformação significativo e ainda em curso, estes dados são paradoxalmente contrariados pela manutenção de um sistema no qual a parceiro ideal ocupa um lugar importante no imaginário cultural. Assim, mesmo que ele demore a aparecer ou dure enquanto houver amor, sua escolha parece ser um assunto que tem favorecido o desenvolvimento de curiosas práticas sociais. Uma delas tem sido utilizada por movimentos da juventude católica que usa o slogan "Eu escolhi esperar" afirmando se tratar

[...] de uma campanha que atua em duas áreas específicas: sexualidade e vida sentimental. Com o objetivo de encorajar, fortalecer e orientar adolescentes, jovens e pais sobre a necessidade de viver uma vida sexualmente pura e emocionalmente saudável, valorizando a importância de saber esperar o tempo certo, a pessoa certa e a forma certa de viverem as experiências nestas duas áreas da melhor maneira (Fonte: http://euescolhiesperar.com/mobilizacao).

Há também startups que tem elaborado aplicativos de smartphones, como o Once e o Tinder, cujos utilizadores dispõem de variados recursos como a localização e o perfil social de eventuais parceiros. A esse movimento se somam outros agentes sociais como gurus espirituais, conselheiros amorosos, agências de encontro, cartomantes e videntes

3 Vale observar que os dados foram sistematizados considerando a nova metodologia empregada pelas Nações Unidas que consideram que os indivíduos em uniões livre ou casamento consensuais são considerados solteiros, o que oculta a proporção de alianças "não-oficiais" ou não ritualizadas. 
A escolha do cônjuge: uma categoria de análise nas Ciências Sociais.

Revista Ensaios, vol. 14, jan-jun de 2019.

que dispõem de inúmeras ferramentas e técnicas para promover o encontro da pessoa amada.

O aparecimento desses agentes é favorecido pelo aumento demográfico, a divisão do trabalho, sua concentração nas cidades mais populosas, o crescimento das comunicações, o desenvolvimento da mobilidade em todas as suas formas, geográfica e profissional, a valorização da intimidade, entre outros fatores. Ocupando um lugar que orginalmente era restrito família essas mudanças favoreceriam o reconhecimento de que as possibilidades de escolha nas sociedades modernas já não são estritamente limitadas pela distância, nem por rígidas barreiras sociais, mas também não são ilimitadas, pois ainda que seja cada vez mais um assunto pessoal e subjetivamente motivado, tende a ser mediado por diferentes atores, o que não as distingue das sociedades consideradas ágrafas ou tradicionais, onde essa mediação é realizada no âmbito do parentesco, sugerindo que ambas detêm limites e prescrições para a aliança.

Escolher com quem casar é, portanto, um tema que chama atenção das pessoas em geral, assim como dos estudiosos referidos neste trabalho, pois ajuda uns e outros a compreender a dinâmica das relações sociais. O presente ensaio, um desdobramento de minha dissertação e se dedica, pois, a contribuir com essa discussão, chamando atenção para a variedade de recortes metodológicos utilizados sobre a questão ao longo do século XX. Seu principal objetivo é sistematizar esses recortes a partir da recorrência com que o assunto fora abordado em diferentes segmentos do pensamento contemporâneo.

\section{A escolha como categoria de análise}

A escolha é um tema caro às ciências sociais. As bases para sua discussão são contemporâneas da filosofia humanista, cuja reflexão é centrada na doutrina de valorização do indivíduo e na oposição ao fanatismo religioso e à estatização política, que sacrificam a liberdade. A importância dada à razão e o advento da ciência como operador cognitivo das explicações sobre a ação humana e os fenômenos da natureza favoreceram, nesse contexto, o progressivo empoderamento do indivíduo, deslocando a autoridade, a tradição e a moral para a periferia da ação social. 
A escolha do cônjuge: uma categoria de análise nas Ciências Sociais.

Revista Ensaios, vol. 14, jan-jun de 2019.

Alexis de Tocqueville foi certamente umas das mais importantes testemunhas oculares dos efeitos que esse movimento produziu no imaginário ocidental. A ideia de liberdade ("e sua eterna vigilância") atravessa tanto a obra Democracia na América como o Antigo Regime e a Revolução (Tocqueville, 1982, 2005). Ao lançarem-se na perseguição da liberdade como ideal e valor, norte-americanos e franceses na verdade atribuem uma ênfase cultural ao individualismo como projeto e visão de mundo. A consciência de que a escolha é um domínio privado e subjetivo torna-se, em razão disso, o principal legado das nações que protagonizaram as revoluções burguesas.

No plano científico a primeira abordagem do assunto no contexto do casamento foi realizada por Galton, em seus Essays in eugenics (Galton, 1909). Neste trabalho, o autor chama a atenção para a soberania das influências sociais sobre as escolhas pessoais, considerando que o casamento nunca foi um assunto de livre escolha, e que as restrições sociais sempre foram universais, pois são elas que direcionam a escolha matrimonial. No plano moral a influência exercida pelos manuais de etiqueta, os guias de casamento e o romance realista tinham a finalidade de orientar seus leitores sobre os modos de agir considerados mais civilizados e cultos para a época (Herman, 1973). O caso mais exemplar é o de Jane Austen, romancista inglesa cuja obra conseguiu reunir diferentes modalidades do discurso na passagem para o século XIX para apontar as diferenças de classe e as estratégias matrimoniais presentes em uma sociedade que estava se industrializando e urbanizando (Wilkes, 2013).

Por mais que originalmente ocupassem as estantes da aristocracia urbana, as ideias contidas nestes livros se difundiram como teses e práticas eugenistas a partir dos movimento médico-higienistas protagonizadas pelo Estado burguês (Costa, 1989; Castañeda, 2003). Uma boa parte desse ideário foi incorporado, conforme demonstra Facina (2004), ao mercado editorial que se especializou em instruir e disciplinar o que ficou conhecido como "boas maneiras". Na forma de manuais essas obras, cada vez mais acessíveis ao público com o processo de urbanização e escolarização da população, colaboraram para o desenvolvimento de um "espírito de distinção" que, ao mesmo tempo, criava e estimulava a produção de um discurso voltado para a identificação e seleção de características e expectativas relativas a associação conjugal socialmente valorizadas, perpetuando na mentalidade daqueles que tinham ou não acesso a essa leitura a ideia de 
A escolha do cônjuge: uma categoria de análise nas Ciências Sociais.

Revista Ensaios, vol. 14, jan-jun de 2019.

que era necessário fazer alianças a partir da aparência física, da origem social e da posição do sujeito na sociedade.

Fortalecida pela consolidação da psicologia como ciência e dos estudos sobre a consciência no século XIX a influência dessas obras fora determinante para o surgimento de padrões de homogamia observados nos países em desenvolvimento (com destaque para os Estados Unidos), onde franceses e britânicos exerciam grande influência ideológica e cultural.

O desenvolvimento e difusão dos estudos sobre a escolha matrimonial, no entanto, assumiram uma nova roupagem ao longo do século XX, pois com sua diversificação - na economia com John von Neumann (Von Neumann \& Morgenstern, 1944) e Kenneth Joseph Arrow (Arrow, 1951), na psiquiatria com Leopold Szondi (Szondi, 2013 [1937]) e William Glasser (Glasser, 2001) e na demografia histórica em razão da contribuição pioneira de Louis Henry (Henry, 1966) - favoreceu sua especialização em diferentes contextos que aqui definiremos como "correntes teórico-metodológicas".

\section{Corrente norte-americana}

A literatura sobre a escolha conjugal dedicada a analisar o papel da vantagem comparativa entre maridos e esposas se desenvolveu nos Estados Unidos da América. Isso porque os primeiros estudos na área foram elaborados seguindo o método quantitativo, pois tinham como objetivo identificar as consequências do crescimento populacional gerado pela migração, da expansão urbana e da ofensiva da indústria cultural na formação dos novos casais em termos de raça, etnia, religião e status socioeconômico. Suas hipóteses normalmente giram em torno das causas da endogamia e homogamia local.

Psicólogos e demógrafos norte-americanos, entre eles Bossard (1939), Popenoe (1937) e Burgess \& Wallin (1943) se interessaram pelo perfil dos noivos universitários a partir do mapeamento de configurações raciais, religiosas e laborais. Posteriormente, Graves \& Graves (1974), Hollingshead (1950), Kirkpatrick \& Caplowe (1945a, 1945b), Sletto (1946), Winch $(1943 ; 1947 ; 1949 ; 1955)$, realizaram estudos com base no método dedutivo, utilizando dados estatísticos obtidos por meio de entrevistas fechadas no meio 
A escolha do cônjuge: uma categoria de análise nas Ciências Sociais.

Revista Ensaios, vol. 14, jan-jun de 2019.

universitário e fabril, ou junto a institutos de migração. A partir dos anos 1980 estudos como os de Coleman (1984), Buss (1985; 1989; 1994), Hechter \& Kanasawa (1997) e Buss e Kenrick (1998) passaram a se interessar pelos elementos racionais implicados no processo de escolha que leva a formação de perfis encontrados em diferentes regiões dos Estados Unidos. Os trabalhos de Goode (1959) e Herman (1973), todavia, são os que se aprofundam na discussão desses perfis. O primeiro porque discute a influência do sentimento de amor na constituição do casamento moderno; já o segundo discorre sobre a influência dos guias de matrimônio na representação sobre o parceiro ideal.

Também os antropólogos, como Barnes (1999), que em seu Marriage by Capture analisa as críticas à teoria de McLennan sobre o noivado por rapto, demonstra que etnografia moderna ofereceria condições mais adequadas para entender que a escolha baseada no amor responde a uma linguagem exogâmica na estrutura do parentesco contemporâneo. Murdock (1949), por sua vez, argumenta que a existência desta linguagem revela a presença de uma série de gradientes de atração e repulsão cujos princípios que o orientam repousariam em padrões ou leis de seleção sexual universais. Partindo de uma visão estruturalista este autor sugere que qualquer propósito presente em uma escolha estaria baseado em um número limitado de critérios fundamentais, alguns deles negativos, como o etnocentrismo, a exogamia, o adultério, a homossexualidade, e outros positivos, como a proximidade geográfica, a idade e o parentesco ${ }^{4}$.

Por fim, em seu estudo sobre os efeitos da desigualdade econômica e de gênero sobre as características das famílias e a reprodução das populações Schwartz (2013) enfatiza que a seleção de parceiros possui tendências e variações que são determinadas pelo nível de coesão das gerações. Reproduzindo um padrão predominante entre os pesquisadores norte-americanos, a autora procura dar ênfase aos critérios de seleção que justificam a existência de padrões endogâmicos e homogâmicos de escolha conjugal, demonstrando que há uma forte tendência para esta corrente se preocupar com a problematização de arranjos que são socialmente compatíveis com uma estrutura fortemente estratificada e hierarquizada.

\footnotetext{
${ }^{4}$ Ver principalmente o capítulo intitulado "Social law of sexual choice" (Murdock, 1949, pp. 314-322).
} 
A escolha do cônjuge: uma categoria de análise nas Ciências Sociais.

Revista Ensaios, vol. 14, jan-jun de 2019.

\section{Corrente Francesa}

A Segunda Guerra Mundial, por sua vez, foi um evento que favoreceu o desenvolvimento das pesquisas sobre a escolha do cônjuge na França. Demógrafos como Alain Girard e Louis Henry, por exemplo, aproveitaram-se do mesmo para avaliar o impacto demográfico que a morte de mais de 50 milhões de pessoas poderia causar sobre os índices de natalidade e a consequente reconstrução dos países afetados pelo armistício. Considerando o contexto de sensíveis transformações em seu quadro familiar, como a chefia feminina - em razão da grande mortandade de homens durante a guerra -, o aumento no número de famílias monoparentais (em consequência disso) e a elevação na taxa de coabitação não oficial, seus estudos, diferentemente do que ocorria do outro lado do Atlântico, buscavam associar uma elevada quantidade de dados estatísticos com pesquisas de campo, dando ênfase, assim, à dinâmica das interações entre os grupos de classes e o efeito dessa interação no modo de operar os casamentos.

O Instituto Nacional de Estatística e Demografia (I.N.E.D) foi um protagonista nesse processo pois estimulou e financiou uma série de projetos voltados para o estudo das transformações que atravessam as famílias europeias desde os anos de 1960, nomeadamente sob o ângulo sociológico, demográfico e genético. Considerado o pioneiro nas discussões sobre o processo de escolha e arranjos matrimoniais, Alain Girard (1964) viu seu trabalho se tornar um dos clássicos da sociologia empírica, pois tinha como tese central o fato de que a escolha do cônjuge não era uma questão de sentimento, mas essencialmente um "fenômeno social". Por seu turno, Louis Henry, em vários artigos (Henry, 1966; 1968; 1969) estudou o processo de escolha e como a população reagia às perturbações causadas por uma guerra ou catástrofes naturais.

Outros autores seguiram os passos deixados por Girard e Henry. Martine Segalen e Albert Jacquard, por exemplo, publicaram os resultados de uma pesquisa em 1971 sobre a história da constituição dos casais de Vraiville, vila operária no interior da França (Segalen \& Jacquard, 1971). Entre os resultados obtidos, os autores perceberam que as associações matrimoniais promoveram o surgimento e posterior desaparecimento de uma classe social bem definida, a dos tecelões, enfatizando que, no decorrer dos anos, as 
A escolha do cônjuge: uma categoria de análise nas Ciências Sociais.

Revista Ensaios, vol. 14, jan-jun de 2019.

mudanças ocorridas na estrutura sócio-profissional desse vilarejo, produziram uma verdadeira mutação na função do casamento. Segundo os autores, como canal de transmissão das heranças, o parentesco favorece, tanto quanto possível, as uniões no interior da parentela. Para os tecelões de Vraiville, o casamento homogâmico (e eventualmente consanguíneo) tinha outra função: visava associar duas forças de trabalho e um bem de produção (o ofício de tecer). Este modelo matrimonial se impôs até as últimas décadas do XIX, quando o modelo matrimonial mais urbano surgiu. Os limites da escolha do cônjuge alargaram-se e a sociedade passou a conviver com outros intermediários (bailes, lugares mistos de trabalho, escolas ou fábricas, etc.). O ideal da escolha, que antes era determinado pela parentela foi, por conseguinte, alterado, tornando a escolha mais dispersa, porque distribuída num cenário mais amplo e com mais variáveis.

Por sua vez, Bourdieu realizou duas pesquisas sobre o campesinato do sudoeste francês que foram importantes para o desenvolvimento da etnologia contemporânea (Bourdieu, 1972; 2002). Nelas o autor destaca as estratégias matrimoniais ("mãos de carta") utilizadas pelo conjunto de parentes para promover a manutenção dos territórios e ao mesmo tempo o papel que a primogenitura, o dote e a lógica das alianças desempenhavam no processo de seleção e escolha do parceiro entre homens e mulheres. Dessa forma, as estratégias matrimoniais que ele estuda são o produto não da obediência à regra, como sugeriam os estudos de parentesco predominantes até então, mas do sentido do jogo que leva a "escolher" o melhor partido possível considerando o jogo que se tem para “jogar”, isto é,

[...] os trunfos e as cartas ruins (as moças particularmente), e a arte de jogar que se possui; é a regra explicita do jogo - por exemplo, os interditos e as preferências em matéria de parentesco ou as leis sucessórias - que define o valor das cartas (rapazes e moças, primogênitos e caçulas). E as regularidades que se podem observar, graças à estatística, são o produto agregado de ações individuais orientadas pelas mesmas coações objetivas (as necessidades inscritas na estrutura do jogo ou parcialmente objetivas em regras) ou incorporadas (o sentido do jogo, ele próprio distribuído de modo desigual, por que em toda parte, em todos os grupos, existem graus de excelência) (Bourdieu, 2004, p. 82).

Bourdieu sugere, portanto, que toda família tem como objetivo único a manutenção ou a expansão de seu capital material e simbólico. No entanto, o casamento de cada um dos filhos de cada família representa um problema específico que necessita de diferentes 
A escolha do cônjuge: uma categoria de análise nas Ciências Sociais.

Revista Ensaios, vol. 14, jan-jun de 2019.

estratégias para assegurar o fim desejado. Como em um jogo de cartas, onde diferentes opções de jogada se colocam conforme o valor da carta, das outras cartas na mão e das regras do jogo, o casamento de cada indivíduo apresenta diferentes alternativas para maximizar os ganhos com a transação matrimonial.

Na década de 1980, Bozon e Herán, após ingressarem no I.N.E.D., lançaram as bases para uma pesquisa que tinha como foco os casais que haviam se unido entre 1960 a 1983. A diferença desta pesquisa para a realizada por Girard, estava no fato de que a categoria 'coabitantes não casados' fora incluída. Em uma de suas coletâneas, Bozon (2006) descreve essa transformação, passando a dar atenção não só às escolhas com vistas ao casamento tradicional, mas também às novas modalidades de arranjo que já vinham sendo vividas pela sociedade francesa daquele período, entre elas a coabitação, que para Girard era uma das novidades que poderia justificar uma investigação mais aprofundada. Suas pesquisas levaram Bozon a concluir que a escolha do cônjuge descansa sobre um jogo de constrangimentos morfológicos, de disposições inconscientes e de finalidades estratégicas (Bozon, 1991; 1992). Para ele, a sociedade, dada sua morfologia e a criação de subconjuntos sociais, cria uma forma de pré-seleção dos indivíduos, determinada pela sua origem social. Sem falar da falta de liberdade, o estudo de Bozon procura mostrar que a escolha de um dos cônjuges é socialmente controlada, tanto individual como coletivamente. Não há, portanto, um forte determinismo social regendo as uniões entre pessoas. Nasceria daí sua ideia de que o príncipe encantado estaria morto!

Em geral, os pesquisadores franceses recusavam-se a aceitar a ideia de que a sociologia da escolha do cônjuge era uma sociologia da família. De fato, associavam-na à Sociologia da Sociabilidade, assim como à Sociologia do Julgamento e das Categorias de Percepção. Interessava-lhes os casos de figuras intermediárias, como os padeiros, então estudados por Daniel Bertaux e Isabelle Bertaux-Wiame (1982), para quem a escolha do cônjuge coincidia com o recrutamento de um colaborador, o que implica numa combinação indissolúvel entre amor e cálculo, relação de confiança e investigação de garantias.

\section{Corrente Latino-americana}


A escolha do cônjuge: uma categoria de análise nas Ciências Sociais.

Revista Ensaios, vol. 14, jan-jun de 2019.

Uma outra corrente de interpretação dos dados referentes a escolha do cônjuge é formada pelos pesquisadores latino-americanos, cuja abordagem privilegia a quantificação dos dados relativos à nupcialidade e à descrição do fenômeno nupcial, tendendo a valorizar aspectos históricos e sócio-antropológicos em sua análise. Em Portugal, por exemplo, os trabalhos mais significativos foram realizados por Almeida (1986), Almeida (1988-1989), Almeida et al (1997), Carneiro (2002), Lages (1983), Leal (1986) e Monteiro (1993) e resultaram de pesquisas em comunidades espalhadas pelo interior do país. Karin Wall e Rodrigo Rosa, por outro lado, buscam generalizar suas análises empregando a metodologia francesa ao discutir o casamento como um fenômeno fusional ao nível afetivo e sexual e, se possível - mas não obrigatoriamente -, fusional em nível profissional e social. Na concepção de Wall (1998), o padrão de escolha conjugal português considera a busca pelo parceiro afetivo um projeto de vida onde, idealmente, a atração mútua, o entendimento e a homogamia profissional protegem a vida conjugal das desavenças graves e, portanto, de qualquer desgaste dos laços susceptíveis de conduzir à ruptura. Enquanto isso, para Rosa $(2008 ; 2005)$ prevalece o interesse em identificar, no processo de formação dos casais, o habitus dos envolvidos segundo o local em que se encontram, numa perspectiva que leva em consideração o contexto social que predispõe os indivíduos a sentir atração, ao mesmo tempo física e simbólica, um pelo outro.

Entre os estudiosos de língua espanhola podemos citar os trabalhos de Carabaña (1983), que analisa o processo de mobilidade social alcançado através do casamento entre membros de diferentes classes sociais espanholas; e Piani (2000), que arrola as variáveis determinantes do mercado matrimonial no Uruguai.

Na Itália o estudo mais significativo se refere à pesquisa de Sinibaldi (2005) que inaugura a discussão sobre a importância de Simmel na explicação do fenômeno da escolha afetiva. Baseada em sua obra "Filosofia do Dinheiro", a autora elabora uma crítica pertinente à aplicação do paradigma econômico ao comportamento humano e assim como àquelas que se dão pela chamada "teoria da troca social". Segundo Sinibaldi a aplicação dos conceitos de valor de troca e da escolha do cônjuge tem permitido o desenvolvimento de conceitos como "mercado matrimonial", comum aos teóricos franceses, e de "complementaridade de necessidades", presente nos estudos norte-americanos. Mostra, dessa forma, que as semelhanças entre o mercado e a seleção de candidatos lança luz 
A escolha do cônjuge: uma categoria de análise nas Ciências Sociais.

Revista Ensaios, vol. 14, jan-jun de 2019.

sobre as condições estatísticas da troca de material e valores simbólicos realizada pelos agentes, e as necessidades e o lucro que cada candidato pretende obter com isso.

O Brasil demonstra protagonismo nesta área tendo publicado estudos relevantes sobre a escolha do cônjuge em diferentes áreas do conhecimento. Na demografia histórica os trabalhos de Marcílio (1973), Bacellar (1997), Botelho (2004) e Lopes (2005) que abordam reconstituição de famílias concentraram suas análises em normas e sistemas jurídicos do processo de escolha em cidades do sudeste e sul do país. Já Almeida (1999), Silva (2003), Torres-Lodoño (1999) e Vainfas (1986), como contraponto, analisaram as práticas transgressivas ou desviantes no período pré-republicano. Ainda na historiografia o trabalho de Nazzari (2001) sobre o declínio do dote em São Paulo deu ênfase ao perfil das alianças e o processo de substituição desse dispositivo no início do século XX. Estudando o mesmo período, Samara (1987/1988) chama a atenção para as estratégias de casamento adotadas durante o boom do café na economia brasileira e a influência dos migrantes na estrutura matrimonial que daí se originou. Pesquisa semelhante foi realizada por Cancela (2006) sobre os arranjos matrimoniais em Belém no período que ficou conhecido como Belle Époque (1870-1920). Del Priore (2007) e Levy (2009) discutem os fatores presentes no processo de formação da sociedade brasileira que culminaram no exercício de uma escolha livre e por amor. Fontenele (2008) apresenta dados sobre decretos que impediam ou estimulavam a miscigenação na era pombalina na Amazônia.

Os trabalhos de Otta (1998) e Laranjeira (2008), e um significativo número de trabalhos na área de psicologia, como os de Carneiro (1997), Ângelo (1995), Anton (2000), Guelfi et al. (2006), Almeida e Oliveira (2007), Silva et al. (2010) e Hattori (2009) dão ênfase ao estudo do ciclo de vida familiar onde aspectos como os modelos transmitidos pelas famílias de origem e a busca por similaridade ou por complementaridade são as motivações mais importantes para a seleção de um parceiro conjugal. A perspectiva psicológica adotada por estes trabalhos demonstra que a escolha estaria relacionada aos modelos parentais onde todo indivíduo, ao tomar como modelo seus pais, construiria um esquema da maneira de se relacionar com um parceiro. Dessa forma, "os valores e as expectativas de cada indivíduo, assim como as ideias de quais características seriam desejáveis no parceiro escolhido, são transmitidos, em grande parte, pelas famílias de origem” (SILVA et al, 2010, p. 384). 
A escolha do cônjuge: uma categoria de análise nas Ciências Sociais.

Revista Ensaios, vol. 14, jan-jun de 2019.

As pesquisas antropológicas, parcialmente influenciados pelo funcionalismo britânico e o estruturalismo francês, se preocupam com o aspecto relacional da escolha. Nesta linha despontam trabalhos cuja ênfase se concentra na análise das estratégias encontradas pelas elites urbanas e agrárias para garantir a manutenção de privilégios políticos e econômicos, ainda que convivam com as transformações do modelo de organização social imprimidas pela modernização. É o caso de Cândido (1979), que estuda os aspectos da cultura "caipira" no interior de São Paulo e demonstra como se processou a formação de casais sob a atenta vigilância das famílias; de Azevedo (1986), que se volta para as manifestações amorosas, procurando demonstrar como o namoro permite construir pontes entre o masculino e o feminino, ao mesmo tempo em que se trata de um mecanismo básico de transformação de estados sociais muito importantes, sobretudo nas sociedades tradicionais; de Viveiros de Castro e Benzaquen de Araújo (1977) que se interessam por isolar a concepção de amor presente na obra Romeu e Julieta de Shakespeare, procurando ao mesmo tempo perceber qual a lógica das relações sociais subsumidas por esta categoria, qual o sistema de oposições e compatibilidades em que ela insere-se, que visão de mundo ajuda a construir com a emergência da vida moderna; de Velho (2006) que procura deixar claro que o casamento representa um jogo de identidades, interesses e valores de grupos, procurando demonstrar que o envolvimento entre duas pessoas envolve não só parentes ou amigos, mas redes de sociabilidade que garantem a manutenção e fortalecimento do casal; de Woortmann (1995) que se empenha em descrever as estratégias de casamento necessárias para assegurar a preservação ao patrimônio representado pela terra em duas diferentes comunidades rurais do Brasil sitiantes no Nordeste e colonos no Sul; de Woortmann (2002) que analisa as contribuições etnológicas de Bourdieu para se compreender a natureza das regularidades matrimoniais, o que não significa obediência a regras, mas práticas de reprodução social sustentadas pelo habitus; e, por último, o trabalho de Dias (2000) que discorre sobre as implicações da imigração cabo-verdiana nos arranjos familiares, com ênfase na análise das representações femininas sobre o padrão ideal de marido.

Apesar de sua relevância teórica e metodológicas, estes estudos compreendiam a escolha do cônjuge como um tópico em suas pesquisas sobre sistemas de aliança e organização social. Os trabalhos dedicados exclusivamente ao tema só se iniciam no final do século XX e se difundem no início deste. 
A escolha do cônjuge: uma categoria de análise nas Ciências Sociais.

Revista Ensaios, vol. 14, jan-jun de 2019.

A etnografia de Adriana Piscitelli (1990) sobe Serro Verde, no sul de Minas Gerais, pode ser considerada o primeiro deles. Em seu trabalho a autora descreve os arranjos matrimoniais das famílias de elite, apresentando dados que indicam a existência de mecanismos socialmente estruturados que regulam as escolhas e estratégias de relacionamento entre os segmentos sociais que compõem a cidade. Fernandes (2005), por sua vez, realizou um estudo sobre a construção das escolhas matrimoniais na cidade de Mossoró no Rio Grande do Norte, no qual identificou a forte presença dos "efeitos de lugar" - no qual valores e condutas socialmente valorizadas integram o sistema classificatório do cônjuge preferencial (BOURDIEU, 1999) - na composição dos arranjos conjugais. Medina (2004), por outro lado, se interessou por uma genealogia da noção de escolha, mas define seu campo de análise a partir de entrevistas e um método muito peculiar de comparação de fotos, cujo objetivo - identificar padrões ideais de parceiro e representações sobre casais ajustados - molda sua preocupação em retratar que, apesar das características individualistas e igualitárias de nossa sociedade e dos indivíduos substituírem o compromisso com a linhagem e a coletividade por outro que enaltece a felicidade e a realização pessoal, o casamento ainda é um fator de manutenção de status e de valores de determinado grupo.

Estes trabalhos têm incentivado o desenvolvimento de pesquisas de caráter etnográfico em vários contextos urbanos, conforme tem demonstrado os pesquisadores do Programa de Pós-Graduação em Ciências Sociais (atualmente Sociologia e Antropologia) da Universidade Federal do Pará. Os principais trabalhos publicados foram os de Lago (2002), que analisa as representações e práticas de namoro de jovens das camadas populares urbanas de na virada do séc. XX para o XXI, traçando um paralelo com as normas vigentes no início do século XX e descritas por Azevedo (1986); Souza (2002), que estuda, dentre outras questões, as representações sobre casamento e parceiro ideal de jovens frequentadores do curso de noivos da paróquia de Santa Terezinha, no bairro do Jurunas, em Belém; Malcher (2002), que analisou a forma com que jovens de camadas médias urbanas concebem a noção de amor e vivenciam suas práticas amorosas no contexto da construção das masculinidades; Aguiar (2009), que se preocupa em analisar os discursos de valorização tanto do casamento quanto da homogamia entre famílias de cearenses em Santarém, no Oeste do Pará; e Alencar (2011), que partindo de uma perspectiva etnográfica e literária analisou o perfil dos casais que frequentaram os 
A escolha do cônjuge: uma categoria de análise nas Ciências Sociais.

Revista Ensaios, vol. 14, jan-jun de 2019.

cursos de noivos promovidos pela igreja católica na cidade de Belém, também no Estado do Pará.

\section{A escolha como ação social}

Ao lado da escolha do nome ou do estilo musical, da carreira profissional e do partido político, a variedade de possibilidades de recortes metodológicos utilizados pelas diferentes correntes identificadas ao longo deste trabalho privilegiaram, com o passar do tempo, a metodologia qualitativa, dando ênfase ao conceito de ação na problematização do assunto. Como este texto explora um recorte que justifique a ascensão da escolha como categoria de análise, a reflexão sobre este conceito torna-se necessário e pertinente, pois estabelece as bases sobre as quais os autores a partir de suas respectivas correntes tentaram solucionar um problema fundamental: os indivíduos escolhem por que se encontram conscientemente livres para agir ou porque estão submetidos a pressões externas e inconscientes?

A literatura disponível permite identificar muitas possibilidades de solução a essa indagação, a maioria delas reunindo justificativas que intercalam racionalidade, motivações afetivas e padrões culturais. Quando esta se assenta na atração e está orientada para a interação afetiva, como o namoro ou noivado, por exemplo, a experiência eletiva demonstra que o agente pratica a ação de escolher (seja pela aproximação, contato, ou troca de olhares) como se estivesse vivendo uma experiência espontânea, razão pela qual, ao ser questionado sobre suas motivações, ele aponta um determinado contexto interacional - um encontro numa festa, na rua, na escola, a proximidade pela vizinhança -, um interesse afetivo-sexual - pela beleza, personalidade ou corpo do parceiro - ou íntimo, o que envolve estados psíquicos e emocionais como prazer pela companhia, carência e sentimento de pena. Porém, quando perguntamos à mesma pessoa se é com o seu atual parceiro que ela espera casar, a tendência é que, além das motivações originais, sejam elencadas outras características como caráter, instrução, renda, origem social, cor, nível de instrução, que o tornem compatível com expectativas definidas e delimitadas que dão conta, por um lado, de um tipo ideal de parceria amorosa e, por outro, de um sujeito que se ajusta a um projeto de sociabilidade conjugal reconhecido e socialmente 
A escolha do cônjuge: uma categoria de análise nas Ciências Sociais.

Revista Ensaios, vol. 14, jan-jun de 2019.

valorizado. Esta é a diferença entre saber se uma preferência existe como mero interesse pessoal (escolha por atração) ou como representação coletiva (escolha como valor), o que sugere a necessidade de entender a escolha como uma forma de ação social.

Na perspectiva de Giddens (2000) para quem a ação reúne tanto a agência, como a capacidade dos sujeitos em fazer coisas e provocar mudanças, como o modo através do qual a relação entre o momento e a totalidade se expressa sob a forma de reprodução social, isto é, sob o viés da estrutura social a qual o sujeito pertence. Visto como processo, a ação nessa concepção recusa qualquer diferenciação entre sincronia e diacronia, ou estática e dinâmica, pois toda decisão ou escolha resulta, a um só tempo, de disposições interna e subjetivamente determinadas como das convenções da cultura na qual o indivíduo fora socializado. Sahlins (2008), por sua vez, argumenta que as pessoas agem face a circunstâncias de acordo com os arranjos e rearranjos contingentes de signos, isto é, com base em seus próprios pressupostos culturais. Por fim, Bourdieu (2009) demonstra que a esfera prática das ações humanas evoca tanto um conhecimento dissimulado das instituições como a liberdade para manipulá-las em seu benefício.

Com efeito, a agência é multideterminada e, conforme assinala Geertz (2008), se apresenta para o indivíduo como um nexo dinâmico de encontro entre uma diversidade de atividades reciprocamente orientadas de atores cuja interação tem significado e consequência. Sua forma quase sempre interlocutória envolve comunicação e, portanto, é baseada em códigos culturais, cujo background individual está sujeito à experiência vivida e ao acúmulo constante e irreversível de narrativas que justificam a ação seletiva baseada em valores. Isto ficou demonstrado em trabalhos anteriores (Alencar, 2011; 2013), quando retratamos pessoas que reagem à pergunta sobre suas motivações para escolher com quem querem casar baseadas na ideia de que há uma "pessoa certa", que apareceu na "hora certa", que "é a minha cara-metade", que "era o nosso destino ficarmos juntos" ou que "Deus quis assim". As narrativas, nestes casos, fazem do espontâneo um acontecimento regulado por princípios valorativos como "o certo", o ideal de complementaridade, a tradição do casamento e o encontro com o extraordinário. Esses elementos desempenham uma função simbólica e sua eficácia é verificada de modo retroativo, uma vez que a escolha é considerada ajustada se ela favorecer a continuidade do vínculo. 
A escolha do cônjuge: uma categoria de análise nas Ciências Sociais.

Revista Ensaios, vol. 14, jan-jun de 2019.

Ainda que teleológicos, estes apontamentos levantam a suspeita de que, ao abordar os elementos invariáveis da escolha racional (perfis e padrões), os estudos que levam em conta as motivações subjetivas se deparam com os imponderáveis culturais comuns na qualificação ou medição das variáveis afetivas (a origem do interesse, o contexto de sua manifestação, o significado da atração). Tal característica é o que determina a impossibilidade de generalizar conclusões obtidas em estudos sobre determinados grupos para sociedades e épocas diferentes, fator que, associado à escola de pensamento a que pertencem os autores, influencia tanto a metodologia empregada na análise dos dados quanto os resultados a que se chega. Assim, é recorrente encontrarmos nas pesquisas mais recentes o interesse em compreender "quem as pessoas escolhem", "o modo como as pessoas são escolhidas" ou "a origem das categorias/motivações sociais que orientam as práticas eletivas".

Sob esta ótica, a escolha do cônjuge como tema de investigação enfrenta uma fragmentação em sua análise. Em parte, porque a forma como os dados foram inicialmente obtidos (censos demográficos, consulta a banco de dados, questionários fechados, entrevistas com casais casados) ou discutidos (ênfase na decisão, mas pouca discussão sobre as motivações) sujeitaram as análises posteriores à padrões com enorme pretensão generalizante ${ }^{5}$. Em virtude disso, a especialização cada vez maior das áreas de conhecimento intensificou a necessidade de um refinamento teórico acerca desses dados permitindo compreender sua relação com as transformações no âmbito da intimidade e que tem produzido fenômenos singulares, como o desenvolvimento do associativismo baseado em redes de solidariedade formados por mulheres vítimas da violência doméstica ou a "compulsão de amar", e que lutam para recuperar a autoestima, superando escolhas malfadadas e a dependência de relacionamentos destrutivos cujas sequelas afetam sua sociabilidade e a interação socioafetiva; o crescimento de agrupamentos juvenis engajados em movimentos conservadores e de caráter religioso, cuja visão de mundo é atravessada por uma ideologia moral e higienista no que se refere à escolha do cônjuge; e a mobilização política de países que são alvo de imigração, cujo noticiário recente tem apontado crises diplomáticas a respeito dos mecanismos criados por instituições e

\footnotetext{
${ }^{5}$ Isto aconteceu principalmente nos Estados Unidos, onde os pesquisadores deram bastante ênfase aos efeitos da urbanização e da migração diante dos padrões homogâmicos e endogamicos predominantes.

${ }^{6}$ No Brasil o caso mais singular é o MADA (Mulheres que Ama Demais Anônimas) que tem sido abordado em estudos como os de Procópio (2007), Pardo (2015) e Peixoto e Heilborn (2016).
} 
A escolha do cônjuge: uma categoria de análise nas Ciências Sociais.

Revista Ensaios, vol. 14, jan-jun de 2019.

agências governamentais que regulam a formação de casais, influenciando ou impedindo a contração de casamentos vistos como socialmente indesejáveis ${ }^{7}$.

A literatura existente sugere também que o estudo sobre a escolha é caracterizado pela preocupação com a variação das formas de associação conjugal, o que necessariamente corresponde a dizer que o tipo de parceria de uma época e lugar afetam o sistema de casamento e a composição familiar, caso da corrente norte-americana. A tendência individualista e hedonista das interações amorosas no contexto ocidental sugerido por estas pesquisas supõe que a forma assumida pela escolha do parceiro na modernidade é um dos principais reflexos da crise de valores enfrentadas pela família ${ }^{8}$. Essa suposição, no entanto, deve ser questionada pelo fato do pensamento individualista permitir que os sujeitos realizem suas escolhas baseados em valores que acompanham a própria transformação social. Assim, a alegação por grupos mais conservadores de que há uma crise generalizada, cujo foro é a liberdade de fazer escolhas, entra em contradição com fato da liberdade ser a principal protagonista do equilíbrio de poderes entre os diferentes segmentos que compõem a sociedade civil.

Com efeito, a discussão sobre a escolha do cônjuge, ainda que limitada a estudos populacionais, vem desempenhando um importante papel na intepretação das transformações sociais recentes estimulando a reflexão sobre o empoderamento feminino, associada à relativização da agência volitiva (se no passado cabia às mulheres o consentimento diante de uma proposta de casamento, cada vez mais elas assumem o protagonismo na relação); a redução proporcional no número de casamentos católicos, que tende a perder seu caráter litúrgico para se transformar num evento festivo e familiar; o aumento das uniões livres e da coabitação antecipada; a revalorização do noivado; a ressignificação do "desquite" e a variação espacial dos locais de encontro, que se

\footnotetext{
${ }^{7}$ Reunidos por institutos ou centros de imigração que se voltam para a apuração do índice de homogamia social, esses dados têm sido frequentemente utilizados por embaixadas e consulados para desestimular seus nativos a casamentos com estrangeiros.

${ }^{8} \mathrm{O}$ uso que se faz do conceito de família neste trabalho corresponde a um projeto emancipador que acompanhou as transformações econômicas e políticas, instituindo novos padrões de comportamento, mas que só foi possível após mudanças na sua realidade exterior (Sarti, 2000).
} 
A escolha do cônjuge: uma categoria de análise nas Ciências Sociais.

Revista Ensaios, vol. 14, jan-jun de 2019.

deslocam dos contextos de vigilância (vizinhança, bairro, clubes, escolas e igrejas) para ambientes públicos (festas, viagens e a internet) ${ }^{9}$.

\section{Considerações Finais}

Foi objetivo deste artigo explorar o conteúdo do conhecimento produzido em torno da escolha conjugal como objeto de estudo e categoria de análise nas ciências sociais. Sua ênfase variou em função dos contextos teórico-metodológicos em que foi abordada, permitindo ser uma variável nos estudos eugênicos onde havia uma tendência para a investigação sobre características físicas, capacidades intelectuais e, finalmente, traços de personalidade com o objetivo de demonstrar "cientificamente" as vantagens de uma escolha baseadas em critérios raciais, assim como foi (e ainda é) relevante nos estudos demográficos quando se procura identificar as transformações provocadas em escala, como a migrações, guerras e eventos naturais.

Em época recente percebe-se uma difusão do interesse por essas pesquisas revelando que o tema é uma pauta importante nas ciências sociais. Porém, se enquanto no passado (antes da criação do INED na França) as pesquisas se interessavam pelo caráter institucional que a escolha desempenhava nos arranjos matrimoniais, pois as publicações relativas a ela funcionavam como instrumento moralizador do comportamento, pesquisadores contemporâneos têm dado atenção para o caráter processual e reflexivo sobre essas escolhas, revelando que para além fatores externos há uma interlocução entre regras sociais e escolhas individuais.

Nesse cenário predomina a desinstitucionalização da coerção familiar e social e a institucionalização de valores individualistas, caracterizados por uma escolha recíproca, baseada em critérios afetivos, sexuais e na noção de amor (Velho, 2006), ainda que seja reconhecida a presença de elementos endogâmicos e homogâmicos na configuração dos arranjos matrimoniais, como o pertencimento étnico e o gosto compartilhado (Bourdieu, 2008).

\footnotetext{
${ }^{9}$ Segundo Bozon (1991) o local do encontro também afeta a evolução do relacionamento, em termos de coabitação, o número de meses antes da primeira relação sexual, o tempo vivido antes do casamento, etc.
} 
A escolha do cônjuge: uma categoria de análise nas Ciências Sociais.

Revista Ensaios, vol. 14, jan-jun de 2019.

O pressuposto da escolha livre em sociedades complexas é, portanto, uma ilusão, pois assim como ocorre nas sociedades tradicionais está regido por mecanismos socialmente estruturados, onde para se gostar de um outro é necessário que ambos compartilhem dos mesmos referenciais simbólicos. Por isso, o que menos importa é saber o que lhes atrai reciprocamente, mas sim em que sistema se estrutura a representação sobre essa escolha, pois embora as aproximações realizam-se, aparentemente, por afinidade eletiva, de fato acontecem através do princípio dos sistemas de gostos que constitui a base sobre a qual os grupos conseguem reconhecer-se (Desrosieres, 1978). A escolha do cônjuge descansaria, assim, sobre "um jogo de constrangimentos morfológicos, de disposições inconscientes e de finalidades estratégicas" (Bozon, 1991, p. 19), pois a morfologia de uma sociedade cria subconjuntos sociais, onde uma préseleção dos indivíduos os conduz a um portfólio de opções não só possíveis como desejáveis. Assim, mesmo que as chamadas escolhas atípicas existam seriam facilmente explicáveis pela influência das origens sociais de cada indivíduo.

Esta explicação, no entanto, não deve ter pretensões deterministas, tão menos se ocupar da realização de previsões. Como alguém que especula sua volta no tempo para mudar a ordem dos acontecimentos em benefício próprio, quem tenta determinar ou prever o que acontece quando alguém escolhe com quem casar faltar-lhe-á sempre o sentido da ação protagonizada pelos sujeitos em interação. $\mathrm{O}$ trabalho do pesquisador que procura entender o sistema de preferências que regulam a escolha do cônjuge é, na verdade, um exercício de interpretação a déjà-vu, pois ele sempre se depara com semelhanças contextuais, que terminam por ser reveladoras de alguns pontos em comum dos inúmeros arranjos sociais existentes.

A atenção dada por alguns pesquisadores a esse tema, portanto, é oportuna, pois a identificação de pontos em comum sujeita a crença de que o encontro de almas supostamente gêmeas pertence ao domínio do circunstancial, do imponderável, do subjetivo à crítica e ao questionamento científico, uma vez que as evidências disponíveis são suficientes para demonstrar que a interação entre os indivíduos é parte inalienável da do senso que leva as pessoas a se reconhecerem como "nós", ou seja, o modo como se opera a construção da identidade em um contexto relacional. 
A escolha do cônjuge: uma categoria de análise nas Ciências Sociais.

Revista Ensaios, vol. 14, jan-jun de 2019.

Tabela 1: Distribuição percentual e variação da população por status conjugal nos países selecionados, por período (1970-2010). (Deve ser inserido na página 3)

\begin{tabular}{|c|c|c|c|c|c|c|}
\hline PERÍODO & 1970-1971 & 1980-1985 & 1990-1999 & 2000-2005 & 2009-2010 & $\begin{array}{l}\text { Variação } \\
(\%)\end{array}$ \\
\hline SOLTEIROS & $(\%)$ & $(\%)$ & $(\%)$ & $(\%)$ & $(\%)$ & 1970-2010 \\
\hline Brasil & 27,9 & 29,6 & 33,2 & 39,0 & 44,2 & $+49,06$ \\
\hline Estados Unidos & 19,0 & 21,5 & 29,1 & 30,8 & 33,7 & $+63,76$ \\
\hline França & 23,3 & 26,1 & 37,3 & 39,6 & 42,2 & $+67,66$ \\
\hline Reino Unido & 22,3 & 23,6 & 28,0 & 27,9 & 39,7 & $+66,41$ \\
\hline CASADOS & $(\%)$ & $(\%)$ & $(\%)$ & $(\%)$ & $(\%)$ & 1970-2010 \\
\hline Brasil & 59,6 & 59,4 & 55,4 & 50,3 & 43,4 & $-29,99$ \\
\hline Estados Unidos & 68,5 & 63,0 & 54,4 & 52,6 & 50,9 & $-28,22$ \\
\hline França & 67,2 & 63,4 & 51,5 & 48,8 & 45,9 & $-35,61$ \\
\hline Reino Unido & 70,2 & 66,9 & 60,0 & 59,5 & 47,2 & $-36,52$ \\
\hline $\begin{array}{l}\text { SEPARADOS/DIVO } \\
\text { RCIADOS }\end{array}$ & $(\%)$ & $(\%)$ & $(\%)$ & $(\%)$ & $(\%)$ & $1970-2010$ \\
\hline Brasil & 3,3 & 3,0 & 4,1 & 4,1 & 6,4 & $+83,67$ \\
\hline Estados Unidos & 5,7 & 9,4 & 10,2 & 11,1 & 11,6 & $+86,75$ \\
\hline França & 2,5 & 4,2 & 6,6 & 7,2 & 7,7 & $+141,18$ \\
\hline Reino Unido & 1,3 & 3,7 & 6,5 & 8,0 & 9,3 & $+299,62$ \\
\hline
\end{tabular}

Fonte: United Nations, Department of Economic and Social Affairs, Population Division (2013). (Deve ser inserido na página 3) 
A escolha do cônjuge: uma categoria de análise nas Ciências Sociais.

Revista Ensaios, vol. 14, jan-jun de 2019.

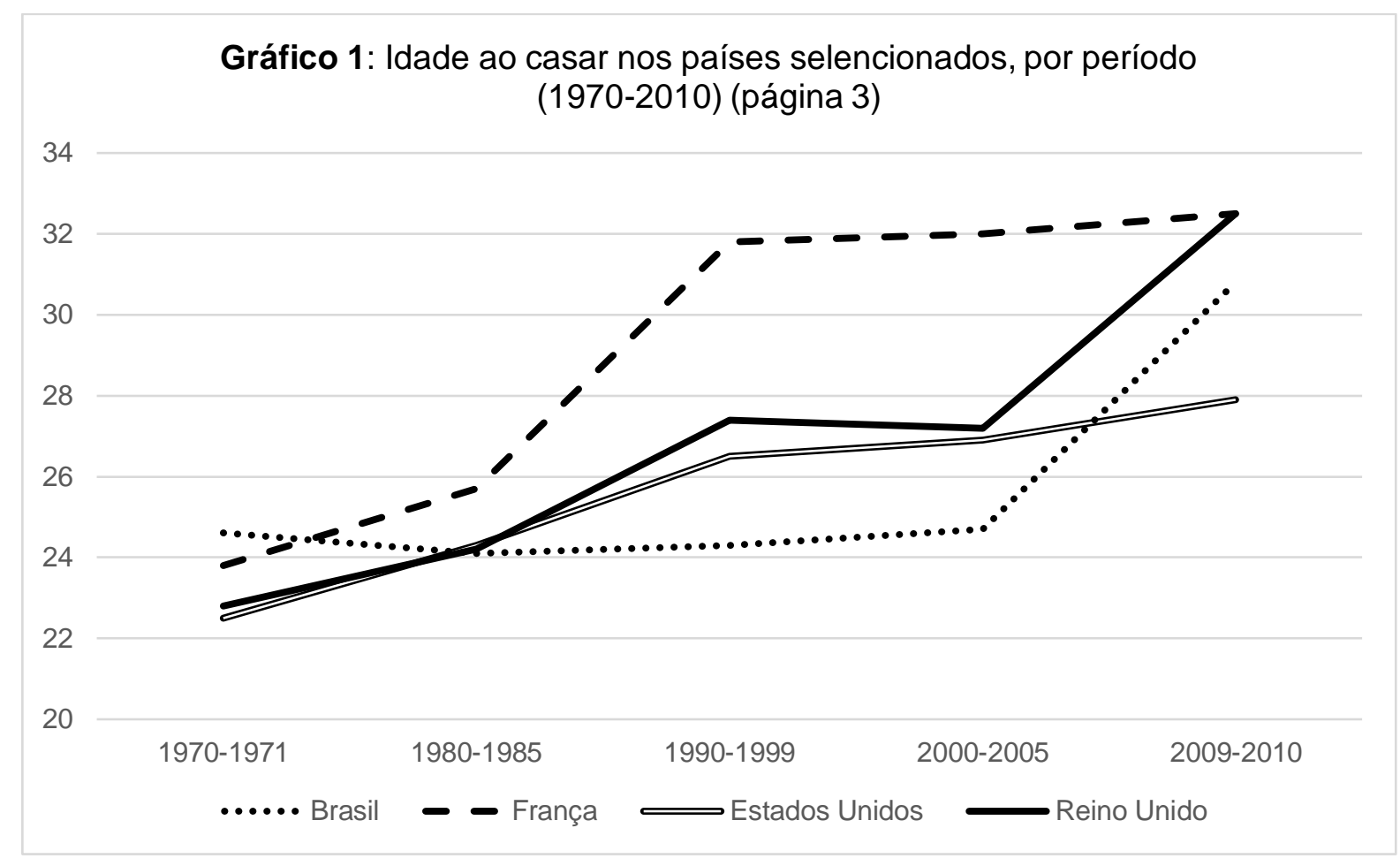

Fonte: United Nations, Department of Economic and Social Affairs, Population Division (2013).

\section{Referências:}

AGUIAR, Keila. (2009), “Quando é da família, é melhor!”: família e casamento entre cearenses em Santarém-Pará. Dissertação de mestrado, Belém, Instituto de Filosofia e Ciências Humanas, UFPA.

ALENCAR, Breno. (2011), Entre a regra e as estratégias: uma abordagem antropológica do processo de escolha do cônjuge. Dissertação de mestrado, Belém, Instituto de Filosofia e Ciências Humanas, UFPA

ALENCAR, Breno. (2013), "A Gente Escolhe Amar": o noivado e as representações sobre o cônjuge ideal. Revista Gênero na Amazônia, Belém, n. 3, jan./jun.

ALLEN, Douglas. (1992), "What Does She See In Him?": The Effect of Sharing On the Choice of Spouse. Economic Inquiry, 30:57-67.

ALMEIDA, Ângelo Mendes. (1988-89), Os manuais portugueses de casamento dos séculos XVI e XVII. Revista Brasileira de História, 9, 17: 1911-1207.

ALMEIDA, Ângela Mendes. (1999), Família e modernidade: o pensamento jurídico brasileiro no século XIX. São Paulo: Porto Calendário.

ALMEIDA, Ana Nunes. (1986), Perspectivas dos jovens sobre a família e o casamento - notas críticas. Análise Social, XXII, 90: 157-164. 
A escolha do cônjuge: uma categoria de análise nas Ciências Sociais.

Revista Ensaios, vol. 14, jan-jun de 2019.

ALMEIDA, Ana Nunes., SOBRAL, José Manuel, \& FERRÃO, João. (1997), Destinos cruzados: estruturas e processos da homogamia. Análise Social, XXXII, 43-44: 875-898.

ALMEIDA, Tiago \& OLIVEIRA, Halley Caixeta. (2007), A importância e a banalização do amor no cotidiano. in Anais da Jornada Apoiar: Saúde Mental nos Ciclos da Vida, São Paulo, pp. 1-16.

ÂNGELO, Claudio. (1995), "A escolha do parceiro" in Maurízio Andolfi, Claudio Angelo e Carmine Saccu (org.), O casal em crise, São Paulo, Summus, pp. 47-57.

ANTON, Iara Camaratta. (2000), A escolha do cônjuge: um entendimento sistêmico e psicodinâmico. Porto Alegre, Artmed.

ARROW, Kenneth. (1951), Social Choice and Individual Values. New York: John Wiley and Sons.

AZEVEDO, Thales de. (1986), As regras do namoro à antiga: aproximações socioculturais. São Paulo, Ática.

BACELLAR, Carlos de Almeida. (1997), Os senhores da terra: família e sistema sucessório entre os senhores de engenho do Oeste paulista, 1765-1855. Campinas, Centro de Memória da UNICAMP.

BARNES, Robert. (1999), Marriage by Capture. The Journal of the Royal Anthropological Institute, 5: 57-73.

BERTAUX, Daniel., \& BERTAUX-WIAME, Isabelle. (1982), L'installation dans la boulangerie artisanal. Sociologie du Travail, 1: 8-23.

BOSSARD, James. (1939), Nationality and Nativity as Factors in Marriage. American Sociological Review, 4: 792-798.

BOTELHO, Tarcisio. (2004), Estratégias matrimoniais entre a população livre de Minas Gerais: Catas Altas do Mato Dentro, 1815-1850, in Anais do XIV Encontro Nacional de Estudos Populacionais, Caxambu, UFMG.

BOURDIEU, Pierre. (1972), Les stratégies matrimoniales dans le système de reproduction. Annales, 4-5: 1105-1125.

BOURDIEU, Pierre. (1999), "Efeitos de lugar", in Em Pierre Bourdieu, A miséria do mundo, Petrópolis, Vozes, pp 159-166.

BOURDIEU, Pierre. (2002), Le Bal des célibataires. Crise de la société paysanne en Béarn. Paris: Seuil.

BOURDIEU, Pierre. (2004), "Da regra as estratégias", in Pierre Bourdieu, Coisas Ditas, São Paulo, Brasiliense, 77-95.

BOURDIEU, Pierre. (2008), A distinção: crítica social do julgamento, São Paulo/Porto Alegre: Edusp/Zouk.

BOURDIEU, Pierre. (2009), "Estruturas, habitus, práticas", in Pierre Bourdieu, O senso prático, Petrópolis, Vozes, pp. 86-107. 
A escolha do cônjuge: uma categoria de análise nas Ciências Sociais.

Revista Ensaios, vol. 14, jan-jun de 2019.

BOZON, Michel. (1991), "Le choix du conjoint", in François de Singly, La famille: l'état des savoirs. Paris: La Découverte, pp. 22-23.

BOZON, Michel. (1992), Sociologie du rituel du mariage. Population, 47, 2: 409-433.

BOZON, Michel. (2006), La formation du couple: textes essentiels pour la sociologie de la famille. Paris: La Découverte.

BURGESS, Ernest., \& WALLIN, Paul. (1943), Homogamy in Social Characteristics. The American Journal of Sociology, 49: 109-124.

BUSS, David. (1985), Human mate selection. American Scientist, 73: 47-51.

BUSS, David. (1989), Sex differences in human mate preferences: evolutionary hypotheses tested in 37 cultures. Behavioral and Brain Sciences, 12, 1: 1-14.

BUSS, David. (1994), The Strategies of Human Mating. American Scientist, 82: 238-249.

BUSS, David., \& KENRICK, Douglas. (1998), "Evolutionary Social Psychology", in Daniel Todd Gilbert, Susan T Fiske, Gardner Lindzey (ed.), The Handbook of Social Psychology, Boston, McGraw-Hill, v. 2, pp. 982-1026.

CANCELA, Cristina Donza. (2006), Casamento e relações familiares na economia da borracha (Belém, 1870-1920), Tese de Doutoramento, São Paulo, Universidade de São Paulo.

CANDIDO, Antonio. (1979), Os Parceiros do Rio Bonito. São Paulo, Livraria Duas Cidades.

CARABAÑA, Julio. (1983), Homogamia y Movilidad Social. Revista Española de Investigación Sociológica, 21: 61-81.

CASTAÑEDA, Luzia Aurelia. (2003), Eugenia e casamento. História, Ciências, Saúde - Manguinhos, Rio de Janeiro, v. 10, n. 3, Dez.

CARNEIRO, J. E. (2002), Namoro e casamento em Rio Tinto. Revista da Faculdade de Letras, 3, 3: 223-244.

COLEMAN, David. (1984), "Marital Choice and geographical mobility" in A. J. BOYCE (Ed.), Symposia of the Societ for the Study of Human Biology, Chicago, University of Chicago Press, pp. 19-55.

COSTA, J. F. (1989), Ordem médica e norma familiar. (3a . ed.). Rio de Janeiro: Edições Graal.

DEL PRIORE, Mary. (2007), Pequena história de amor conjugal no Ocidente Moderno. Estudos de Religião, XXI, 33: 121-135.

DESROSIERES, Alain. (1978), Marché matrimonial et structure dês classes socials. Actes de la recherche en sciences sociales, 20, 1: 97-107.

DIAS, Juliana Braz. (2000), "Estratégias Familiares no Jogo Matrimonial" in J. B. DIAS, Entre Partidas e Regressos: tecendo relações familiares em Cabo Verde, Brasília, Universidade Nacional de Brasília, pp. 78-133.

FACINA, Adriana. (2004), Literatura e sociedade. Rio de Janeiro, Zahar. 
A escolha do cônjuge: uma categoria de análise nas Ciências Sociais.

Revista Ensaios, vol. 14, jan-jun de 2019.

FERES-CARNEIRO, Terezinha. (1997), A escolha amorosa e interação conjugal na heterossexualidade e na homossexualidade. Psicologia: Reflexão e Crítica, 10, 2: 351-368.

FERNANDES, Mirian Alves. (2005), Escolhendo com quem casar: faces ambivalentes do casamento no Bairro Alto da Conceição - Mossoró (RN). Tese de mestrado, Recife, Universidade Federal de Pernambuco.

FONTENELE, Fracisca Nescilene. (2008), "Casamentos Mistos: um agenciamento da Política Pombalina", in F. N. FONTENELE, Grão-Pará Pombalina: Trabalho, desigualdade e relações de poder. Tese de doutoramento, São Paulo, Pontífice Universidade Católica de São Paulo.

GALTON, Francis. (1909), Essay in eugenics. Londres, The Eugenics Education Society.

GEERTZ, Clifford. (2008), A interpretação das culturas. Rio de Janeiro, LTC.

GIDDENS, Anthony. (2000), "A teoria da estruturação", in A. GIDDENS, Dualidade da estrutura: agência e estrutura, Oeiras, Celta, pp. 43-50

GIRARD, Alain. (1964), Le choix du conjoint: une enquete psycho-sociologique en France. Population, 19, 4: 727-732.

GIRARD, Alain. (1981), Le choix du conjoint: une enquete psycho-sociologique en France. Institut National d'études démographiques, Presses Universitaires de France.

GLASSER, William. (2001), Teoria da Escolha. Uma Nova Psicologia de Liberdade Pessoal. São Paulo, Mercuryo.

GOODE, William. (1959), The Theoretical Importance of Love. American Sociological Review, 24: 38-47.

GRAVES, Nancy., \& GRAVES, Theodore. (1974), Adaptive strategies in urban migration. Annual Review of Anthropology, 3: 117-151.

GUELFI, Evelin Cristina; FRASSON, Cláudia Algoso; BALTAZAR, José Antônio. (2006), Análise dos fatores que levaram à escolha do cônjuge em indivíduos pesquisados na cidade de londrina e região. Terra e Cultura, 22, 43: 81-89.

HATTORI, Wallisen Tadashi. (2009), Escolha de parceiros na adolescência. Tese de mestrado, Natal, Universidade Federal do Rio Grande do Norte.

HECHTER,Michael; KANAZAWA, Satoshi. (1997), Sociological Rational Choice Theory. Annual Review Sociological, 23: 191-214.

HENRY, Louis. (1966). Perturbations de la nuptialité résultant de la guerre 1914-1918. Population, 21: 273-332.

HENRY, Louis. (1966), Perturbations de la nuptialité résultant de la guerre 1914-1918. Population, 21, 2: 273-332.

HENRY, Louis. (1968), Problèmes de la nuptialité. Considérations de méthode. Population, 23, 5: 835-844.

HENRY, Louis. (1969), Schémas de nuptialité: déséquilibre des sexes et âge au mariage. Population, 24, 6: 1067-1122. 
A escolha do cônjuge: uma categoria de análise nas Ciências Sociais.

Revista Ensaios, vol. 14, jan-jun de 2019.

HERMAN, Sondra. (1973), Loving Courtship or the Marriage Market? The Ideal and its Critics 1871-1911. American Quarterly, 25: 235-252.

HOLLINGSHEAD, August. (1950), Cultural Factors in the Selection of Marriage Mates. American Sociological Review, 15: 619-627.

IBGE. (2010), Síntese de Indicadores Sociais. Rio de Janeiro, IBGE.

KIRKPATRICK, Clifford; CAPLOW, Theodore. (1945), Courtship in a Group of Minnesota Students. The American Journal of Sociology, 51: 114-125.

KIRKPATRICK, Clifford; CAPLOW, Theodore. (1945), Emotional Trends in the Courtship Experience of College Students as Expressed by Graphs with some Observations on Methodological Implications. American Sociological Review, 10: 619-626.

LAGES, Mario. (1983). O casamento exolocal numa aldeia da Beira Alta. Análise Social, XIX: 645-665.

LARANJEIRA, Adriano Gonçalves. (2008), "Representações da mulher no tratado do amor cortês de André Capelão", in Anais do Encontro Estadual de História: Poder, Cultura e Diversidade, Salvador, UESB.

LEAL, Ivone. (1986), A mulher e o amor no século XVI: afectividade, sexualidade, casamento: uma abordagem do tema. Análise Social, XXII, 92-93: 769-778.

LEVY, Maria Stella Ferreira. (2009), A escolha do cônjuge. Revista Brasileira de Estudos Populacionai, 26, 1: 117-133.

LOPES, Janaina Christina Perrayon. (2005), Casamentos de escravos e forros nas freguesias da Candelária, São Francisco Xavier e Jacarepaguá: uma contribuição aos padrões de sociabilidade marital no Rio de Janeiro (c.1800-c. 1850). In Anais do Colóquio do LAHES, Juiz de Fora.

MARCÍLIO, Maria Luiza. (1973), A cidade de São Paulo: povoamento e população, 1750-1850. São Paulo, Pioneira/EDUSP.

MONTEIRO, Nuno Gonçalo. (1993), Casamento, celibato e reprodução social: a aristocracia portuguesa nos séculos XVII e XVIII. Análise Social, XXVII, 123-124: 921-950.

MURDOCK, George Peter. (1949), "Social Law of Sexual Choice", in G. P. MURDOCK, Social Estructure, New York/London: The Macmillan Company/Collier-Macmillan Limited, pp. 314322.

NAZZARI, Muriel. (2001), O desaparecimento do dote: mulheres, famílias e mudança social em São Paulo, Brasil, 1600-1900. São Paulo, Companhia das Letras.

OTTA, Emma; QUEIROZ, Renato da Silva; CAMPOS, Lucila de Sousa; SILVA, Monika Weronika Dowbor; SILVEIRA, Mariana Telles. (1998), Escolha de parceiros heterossexuais: um estudo de proclamas de casamento. InterAÇÃO, 2: 97-112.

PARDO, A. J. (2012), Quando amar é sofrer: Um estudo etnográfico no grupo de ajuda mutua MADA. Disssertação de mestrado, Rio de Janeiro, Universidade Estadual do Rio de Janeiro.

PEIXOTO, Mônica Monteiro; HEILBORN, Maria Luiza. (2016), Mulheres que amam demais: conjugalidades e narrativas de experiência de sofrimento. Estudos Feministas, 24: 45-62. 
A escolha do cônjuge: uma categoria de análise nas Ciências Sociais.

Revista Ensaios, vol. 14, jan-jun de 2019.

PIANI, Giorgina. (2000), ¿Quién se casa con quién? Homogamia educativa en las parejas de Montevideo y Zona Metropolitana. Montevideo, Universidade de la República.

PISCITELLI, Adriana. (1990), Amor, paixão e casamento: Escolhas de cônjuge em famílias de camadas médias e altas do sul de Minas Gerais. Tese de mestrado, Campinas, Instituto de Filosofia e Ciências Humanas.

POPENOE, Paul. (1937), Mate Selection. American Sociological Review, 2: 735-743.

PROCÓPIO, Adélia de Souza. (2007), Quando amar é sofrer: um estudo dos discursos sobre gênero e afetividade das Mulheres Que Amam Demais. Tese de mestrado, Goiânia, Universidade Federal de Goiás.

ROSA, Rodrigo. (2005), "A escolha do cônjuge", in K. WALL, Famílias em Portugal: percursos, interacções, redes sociais. Lisboa, Imprensa de Ciências Sociais, pp. 117-161.

ROSA, Rodrigo. (2008), Escolha do cônjuge e modos de construção da distância social no casal. Lisboa: ISCTE.

SAHLINS, Marshall. (2008), Metáforas históricas e realidades míticas. Rio de Janeiro, Zahar.

SÂMARA, Eni Mesquita. (1987/1988), Estratégias Matrimoniais no Brasil do Século XIX. Revista Brasileira de História, 8, 15: 91-105.

SARTI, Cynthia. (2000), "Família e individualidade, um problema moderno" in Maria do Carmo Brant de Carvalho, A família contemporânea em debate, São Paulo, Cortez, pp. 39-49.

SCHUTZ, Alfred. (2012), Sobre fenomenologia e relações sociais. Petrópolis, Vozes.

SCHWARTZ, Christine R. (2013), Trends and Variation in Assortative Mating: Causes and Consequences. Annual Review of Sociology, 39:451-470.

SEGALEN, Martine., \& JACQUARD, Albert. (1971), Choix du conjoint et homogamie. Population, 26, 3: 487-498.

SILVA, Isabela Machado, MENEZES, C. C., \& LOPES, R. C. (2010), Em busca da "carametade": motivações para a escolha do cônjuge. Estud. psicol., 27, 3: 383-391.

SILVA, Maria da Conceição. (2003), Catolicismo e casamento civil na Cidade de Goiás: conflitos políticos e religiosos (1860-1920). Revista Brasileira de História, 23, 43: 123-146.

SINIBALDI, Silvia. (2005), Valore dei beni e valori della persona: la scelta del coniuge in un comune della Val di Chiana nel corso del 20. secolo. Tese de doutoramento, Siena, Facoltà di Lettere e Filosofia, Università degli Studi di Siena.

SLETTO, Raymond. (1946), Interrelations between Certain Social Background and Paren-Son Factors in a Study of Courtship among College Men: Disscusion. American Sociological Review, 11: 341-343.

SZONDI, Léopold. (2013 [1937]), Introdução à psicologia do destino. São Paulo, Realizações.

TOCQUEVILLE, Alexis. (1982). O Antigo Regime e a Revolução. Brasília, Editora da UnB.

TOCQUEVILLE, Alexis. (2005). A Democracia na América. São Paulo, Martins Fontes. 
A escolha do cônjuge: uma categoria de análise nas Ciências Sociais.

Revista Ensaios, vol. 14, jan-jun de 2019.

TORRES-LODOÑO, Fernando. (1999). A outra família: concubinato, Igreja e escândalo na Colônia. São Paulo, Loyola.

VAINFAS, Ronaldo. (1986). História e sexualidade no Brasil. Rio de Janeiro, Graal.

VELHO, Gilberto. (2006). Subjetividade e sociedade: uma experiência de geração. Rio de Janeiro, Zahar.

VIVEIROS DE CASTRO, Eduardo., \& ARAÚJO, R. B. (1977), "Romeu e Julieta e a origem do Estado", in G. VELHO, Arte e Sociedade: ensaios de sociologia da arte, Rio de Janeiro, Zahar, pp. 130-169.

VON NEUMANN, John., \& MORGENSTERN, Oskar. (1944), Game theory and economic behavior. Princeton, Princeton University.

WALL, Karin. (1998), Famílias no campo: passado e presente em duas freguesias do Baixo Minho. Lisboa, Publicações Dom Quixote.

WILKES, Christopher. (2013), Social Jane: The Small, Secret Sociology of Jane Austen. Cambridge, Cambridge Scholars Publishing.

WINCH, Robert. (1943), The relation between courtship behavior and attitudes towards parents among college men. American Sociological Review, 8: 269-174.

WINCH, Robert. (1947), Primary Factors in a Study of Courtship. American Sociological Review, 12: 658-666.

WINCH, Robert. (1949), Courtship in College Women. The American Journal of Sociology, 55: 269-278.

WINCH, Robert. (1955), The Theory of Complementary Needs in Mate-Selection: A Test of One Kind of Complementariness. American Sociological Review, 20: 52-56.

WOORTMANN, Ellen. (1995), Herdeiros, parentes e compadres: colonos do Sul e sitiantes do Nordeste. São Paulo/Brasília, Hucitec.

WOORTMANN, Klaas. (2002), A Idéia de Família em Malinowski. Campos, 2: 7-32. 